\title{
Discussion on Reliability of Narrow-band TD-LTE Network Transmission for Distribution Automation System
}

\author{
CHEN Yong-tao ${ }^{1}$, WANG Hao ${ }^{1 \mathrm{a}}$, WANG Min ${ }^{1}$ \\ ${ }^{1}$ Guangzhou Power Supply Co.Ltd. , Guangzhou, Guangdong, 510000, China
}

\begin{abstract}
In Guangzhou, there is a poor communication between power control systems in equipment rooms and the 100,000 distribution terminals scattered around the city. Guangzhou Power Supply Co.Ltd. (CZPS) planned to upgrade smart power distribution grid with wireless communications technology. It built an integrated data collection platform and several small-scale test zones to collect and analyze data from a pilot. In the GZPS Communication Laboratory, to confirm the reliability and accuracy, the transmission performance indicator of DTU are compared with different RSRP by using wireless public network (GPRS) ,230MHz and $1.8 \mathrm{GHz}$ wireless private network testing system.

Keywords: Power Grid Wireless Private Network; Distribution Automation; Remote Control, TD-LTE
\end{abstract}

\section{Introduction}

Power communication service has widely used various communication technologies. With the development of the construction of the smart grid, distribution automation system (DAS) is not just a remote control but it results into a highly reliable,efficient power system that responds rapidly to real-time events with appropriate actions.

The distribution grids have a complex network topology by feeding the power in a wide coverage area. At present, optical fiber communications are the main communication means for the access networks. However, in well-established urban areas that feature complicated terrains and tall buildings, routing of optical fibers is difficult and the costs are often very high. The power wireless private network construction attracts more and more attention. In this scenario, the LTE-based private wireless network can be used as the alternative and economic access network. It is a cost-effective solution to the last-kilometer problem.

Public networks failed to meet service requirements because of poor security, high lease costs, and insufficient service resources. The private wireless network is a solution that eased construction problems and freed wired networks from environmental restrictions. Wireless broadband private network also overcame the poor performance and limited resources of $2 \mathrm{G} / 3 \mathrm{G}$ public networks.

\subsection{Time-Division Long-Term Evolution (TD- LTE) technology}

The solution uses 4G TD-LTE base stations in existing substations and office buildings. The base

\footnotetext{
a Corresponding author: wanghao_hust@163.com
}

stations operate on a $1.8 \mathrm{G}$ and $230 \mathrm{MHz}$ industrydedicated wireless spectrum. In addition, it deployed dedicated TD-LTE distribution terminals with Data Transformation Units (DTUs), Remote Metering Terminal, and Video Surveillance. The base stations combine data from multiple electric power terminals and send it via an existing transmission network to a host station.

\subsection{Multi-level Quality of Service (QoS)}

Different service applications in automatic power distribution networks work on different priorities. Private network TD-LTE system integrates radio resource management and tailored priorities for electricity services. The solution also supports multiple services while ensuring that important data, such as automatic remote service data, transmits preferentially. The QoS mechanism works with real-time online terminals and a latency minimizing solution to ensure less than $100 \mathrm{~ms}$ end-to-end latency. The TD-LTE solution also uses an array of end-to-end data protection methods, including 128-bit Advanced Encryption Standard (AES) and authentication encryption, to ensure high data security and reliability.

\section{Performance Indicators Testing}

In the Guangzhou Power Supply Co. Ltd. (GZPS) Communication Laboratory, to confirm the reliability and accuracy, the transmission performance indicator of DTU are compared with different RSRP by using wireless public network (GPRS), TD-LTE $230 \mathrm{MHz}$ and TD-LTE $1.8 \mathrm{GHz}$ wireless private network testing system. The experiment Results is shown in Appendix I. 


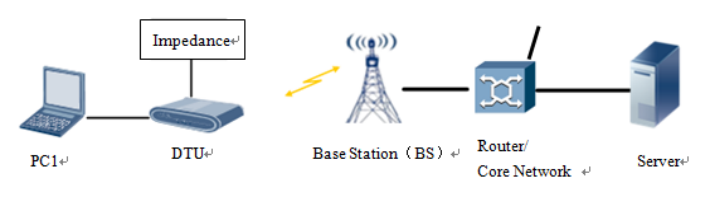

Figure 1.Testing environment.

\subsection{Channel Performances}

There is a positive correlation between the channel uplink /downlink speed and RSRP, its decline from large to small order is $230 \mathrm{MHz}$ network, $1.8 \mathrm{GHz}$ network, GPRS network. Besides, The packet delay and packet loss is positively related to the RSRP. The channel can remain the same under the condition of stable,

TD-LTE is the next-generation wireless broadband technology, using a variety of advanced wireless communication technologies such as Orthogonal Frequency Division Multiplexing (OFDM), Multi-Input Multi-Output (MIMO), a multi-channel smart antenna technology and so on, which effectively enhance the data throughput rate, coverage and the number of user online. GPRS is a best-effort service, implying variable throughput and latency that depend on the number of other users sharing the service concurrently.

\subsection{Communication Requirements}

The distribution equipment can be divided into three categories: remote measuring, remote communication, remote control(three-remote system). Currently, the transmission requirements of distribution automation system are that the largest bandwidth is not less than 64bps; packet delay is not greater than 1 second. The experiment results show that the public network GPRS and private network (TD-LTE $230 \mathrm{MHz}$, TD-LTE $1.8 \mathrm{GHz}$ ) all can satisfy the requirement of three-remote system. In addition, all the operations of switching device were controlled successfully with $1 \mathrm{k}$ uplink data, its purpose is to simulate the real remote signaling by loading $1 \mathrm{k}$ data.

\subsection{Benefits of Private Wireless Network}

Bandwidth of Public network GPRS is $20 \mathrm{Kbps}-$ $40 \mathrm{kbps}$ and latency is 2 second. Experimental results show that the uplink and downlink speed remain at $5 \mathrm{~KB} / \mathrm{s}, 10 \mathrm{~KB} / \mathrm{s}$ respectively, but a gradual increase in the proportion of the retransmission packets. Compared with the TD-LTE network, the pubic GPRS is low reliability and security, its recourses shared by public and network controlled by operators.

Currently, the approved bandwidth of the $1.8 \mathrm{GHz}$ wireless private network is $5 \mathrm{MHz}$. the testing results show that the maximum throughput of uplink and downlink are $1.95 \mathrm{Mbps} 2.27 \mathrm{Mbps}$ respectively. Besides, the 1.8G CPE device support multiple uplink/downlink ratio configuration, including $0(3: 1), 1(2: 2), 2(1: 3)$ (uplink: downlink). It also offer flexible bandwidth from $5 \mathrm{Mhz}$ to $20 \mathrm{Mhz}$. it is adapt for streaming data-intensive uplink service such as video surveillance and data collection.

TD-LTE 230 system uses Adaptation Modulation and Coding (AMC), which can offer an alternative link adaptation method that promises to raise the overall system capacity [1]. AMC provides the flexibility to match the modulation-coding scheme to the average channel conditions for each user. With AMC, the power of the transmitted signal is held constant over a frame interval, and the modulation and coding format is changed to match the current received signal quality or channel conditions. The AMC scheme of TD-LTE 230 system uses QPSK, 8-PSK and 16 and 64 QAM modulation using $\mathrm{R}=1 / 2$ and $\mathrm{R}=3 / 4$ Turbo code. In table 4.2 , it shows that the uplink and downlink speed of LCM change with channel quality. In a system with AMC, the modulation-order or code rate will increase as the quality of channel increases (e.g. 64QAM with $\mathrm{R}=3 / 4$ turbo codes). The maximum uplink speed can reach $45.6 \mathrm{kbps}$. In order to ensure the reliability, it is typically assigned lower order modulation with lower code rates when the quality of channel decreases.

According to the State Radio Regulatory Commission frequency allocation strategy, there are 35 available frequencies for TD-LTE 230. If available frequencies are sufficiently used, the uplink and downlink speed will achieve $1.51 \mathrm{Mbps}$ and $289.5 \mathrm{~Kb} / \mathrm{s}$ respectively

\subsection{The Reliability of Three Remote}

As shown in the experimental results, the RSRP limit of the GPRS public network is $-95 \mathrm{~dB}$, the RSRP limit of $1.8 \mathrm{GHz}$ private network is $-117 \mathrm{~dB}$, the RSRP limit of $230 \mathrm{MHz}$ private network $-121 \mathrm{~dB}$ for multi-frequency, $127 \mathrm{~dB}$ for single frequency. The private network can tolerate lower RSRP than public network, and the channel is more stable. When RSRP $=-97 \mathrm{~dB}$, the GPRS channel is extremely unstable, the Dial-Up networking could not complete the connection to the server. Even if successful connection, the three remote function cannot work properly. When RSRP $=-120 \mathrm{~dB}$, the channel of private network is starting to become unstable, it will take a lot of time to connect successfully. Once the connection is established successfully, the three remote function can work well.

Compared to the GPRS public network, the TD-LTE private network is little time-delay,low packet loss rate, less retransmission rate, so the round trip time of remote control commands and shift information is expected to be much lower. 
Table 1. AS the RSRP $=-90 \mathrm{dBm}$, a brief description of time delay are listed below

\begin{tabular}{|c|c|c|c|c|}
\hline & GPRS & TD-LTE 1.8Ghz & LCM & CPE \\
\cline { 3 - 4 } & & $33 \mathrm{~ms}$ & $181 \mathrm{~ms}$ & $145 \mathrm{~ms}$ \\
\hline $\begin{array}{c}\text { Non-business } \\
\text { state }\end{array}$ & $333.2 \mathrm{~ms}$ & $32 \mathrm{~ms}$ & $162 \mathrm{~ms}$ & $131 \mathrm{~ms}$ \\
\hline $\begin{array}{c}\text { In-business } \\
\text { state }\end{array}$ & & & \\
\hline
\end{tabular}

Table 2. As the channel is stable, the average time of three remote is list below.

\begin{tabular}{|c|c|c|c|c|}
\hline \multirow{2}{*}{ Gwitch on } & GPRS & TD-LTE 1.8GHz & \multicolumn{2}{|c|}{ TD-LTE 230MHz } \\
\cline { 3 - 5 } & $7832 \mathrm{~ms}$ & $2476 \mathrm{~ms}$ & $2808 \mathrm{~ms}$ & $2939 \mathrm{~ms}$ \\
\hline Switch off & $8205 \mathrm{~ms}$ & $3141 \mathrm{~ms}$ & $2821 \mathrm{~ms}$ & $3046 \mathrm{~ms}$ \\
\hline
\end{tabular}

Table 3. The measurement of GPRS network

\begin{tabular}{|c|c|c|c|c|c|c|c|c|c|c|}
\hline \multirow[b]{2}{*}{$\begin{array}{l}\text { Impedace } \\
\text { (dB) }\end{array}$} & \multirow[b]{2}{*}{$\begin{array}{l}\text { RSRP } \\
(\mathrm{dB})\end{array}$} & \multirow{2}{*}{$\begin{array}{c}\text { Uplink } \\
\text { speed(Kb } \\
\text { ps) }\end{array}$} & \multirow{2}{*}{$\begin{array}{c}\text { Downlink } \\
\text { speed }(\mathrm{Kb} \\
\mathrm{ps})\end{array}$} & \multirow{2}{*}{$\begin{array}{l}\text { Packet } \\
\text { Delay } \\
(\mathrm{ms})\end{array}$} & \multirow{2}{*}{$\begin{array}{l}\text { Packet } \\
\text { Loss } \\
(\%)\end{array}$} & \multirow{2}{*}{$\begin{array}{c}\text { Packet } \\
\text { Delay } \\
\text { with } \\
1 \mathrm{k} \\
\text { uplink }\end{array}$} & \multirow{2}{*}{$\begin{array}{l}\text { Packet } \\
\text { Loss }\end{array}$} & \multicolumn{2}{|c|}{ Three remote test } & \multirow[b]{2}{*}{ Accuracy } \\
\hline & & & & & & & & $\begin{array}{l}\text { Switch- } \\
\text { off(ms) }\end{array}$ & $\begin{array}{l}\text { Switch- } \\
\text { on(ms) }\end{array}$ & \\
\hline$+0 \mathrm{~dB}$ & -65 & 5 & 10.8 & 335 & $0 \%$ & 410.5 & $0 \%$ & 7622 & 7575 & $100 \%$ \\
\hline$+5 \mathrm{~dB}$ & -70 & 5 & 10.1 & 343.6 & $0 \%$ & 356.9 & $0 \%$ & 7565 & 8080 & $100 \%$ \\
\hline$+10 \mathrm{~dB}$ & -75 & 5.2 & 11 & 367.4 & $0 \%$ & 346.9 & $0 \%$ & 5050 & 7571.5 & $100 \%$ \\
\hline$+15 \mathrm{~dB}$ & -81 & 5.1 & 10.5 & 316 & $0 \%$ & 347.7 & $0 \%$ & 12120 & 7070 & $100 \%$ \\
\hline$+20 \mathrm{~dB}$ & -85 & 5.1 & 10.1 & 323.4 & $0 \%$ & 427.6 & $0 \%$ & 7575 & 9090 & $100 \%$ \\
\hline$+25 \mathrm{~dB}$ & -90 & 5 & 10.0 & 333.2 & $0 \%$ & 398.2 & $0 \%$ & 7070 & 8585 & $100 \%$ \\
\hline$+30 \mathrm{~dB}$ & -95 & 4.9 & 11.3 & 331.4 & $0 \%$ & 359.1 & $0 \%$ & 8080 & 8585 & $100 \%$ \\
\hline$+32 \mathrm{~dB}$ & -97 & 5.2 & Instable & 324.4 & $0 \%$ & 387.5 & $0 \%$ & 7576.5 & 9090 & $100 \%$ \\
\hline$+34 \mathrm{~dB}$ & -98 & 5.2 & Instable & 324.4 & $0 \%$ & 387.5 & $0 \%$ & Instable & Instable & Instable \\
\hline \multirow{3}{*}{$+35 \mathrm{~dB}$} & \multirow{3}{*}{-99} & \multirow{3}{*}{5.1} & \multirow{3}{*}{ Instable } & 1203.7 & $0 \%$ & 514.8 & $0 \%$ & \multirow{3}{*}{7095} & \multirow{3}{*}{8111.5} & \multirow{3}{*}{$100 \%$} \\
\hline & & & & 618.6 & $5 \%$ & 837.2 & $0 \%$ & & & \\
\hline & & & & 645.1 & $0 \%$ & 566.3 & $11 \%$ & & & \\
\hline \multirow{3}{*}{$+37 \mathrm{~dB}$} & \multirow{3}{*}{-101} & \multirow{3}{*}{5.2} & \multirow{3}{*}{ Instable } & 865.4 & $57 \% /$ & 1125.7 & $9 \%$ & \multirow{3}{*}{ Instable } & \multirow{3}{*}{ Instable } & \multirow{3}{*}{ Instable } \\
\hline & & & & 690.5 & $16 \%$ & 485 & $2 \%$ & & & \\
\hline & & & & 2400 & $40 \%$ & 384.3 & $5 \%$ & & & \\
\hline
\end{tabular}


Table 4. The measurement of TD-LTE 1.8GHz Network

\begin{tabular}{|c|c|c|c|c|c|c|c|c|c|c|}
\hline \multirow{2}{*}{$\begin{array}{l}\text { Impedace } \\
\text { (dB) }\end{array}$} & \multirow{2}{*}{$\begin{array}{l}\text { RSRP } \\
(\mathrm{dB})\end{array}$} & \multirow{2}{*}{$\begin{array}{c}\text { Uplink } \\
\text { speed(Kbp } \\
\text { s) }\end{array}$} & \multirow{2}{*}{$\begin{array}{c}\text { Downlink } \\
\text { speed(Kbp) }\end{array}$} & \multirow{2}{*}{$\begin{array}{l}\text { Packet } \\
\text { Delay } \\
(\mathrm{ms})\end{array}$} & \multirow{2}{*}{ BER } & \multirow{2}{*}{$\begin{array}{c}\text { Packet } \\
\text { Delay } \\
\text { with 1k } \\
\text { uplink }\end{array}$} & \multirow{2}{*}{ BER } & \multicolumn{2}{|c|}{ Three remote test } & \multirow{2}{*}{$\begin{array}{c}\text { Three } \\
\text { remote } \\
\text { test }\end{array}$} \\
\hline & & & & & & & & $\begin{array}{l}\text { Switch- } \\
\text { off(ms) }\end{array}$ & $\begin{array}{l}\text { Switch- } \\
\text { off(ms) }\end{array}$ & \\
\hline$+0 \mathrm{~dB}$ & -92 & 1.95 & 2.27 & 33 & 0 & 32 & 0 & 3030 & 2530 & $100 \%$ \\
\hline$+5 \mathrm{~dB}$ & -97 & 1.12 & 2.38 & 31 & 0 & 32 & 0 & 3015 & 4040 & $100 \%$ \\
\hline$+10 \mathrm{~dB}$ & -103 & 0.684 & 2.24 & 34 & 0 & 34 & 0 & 2020 & 3030 & $100 \%$ \\
\hline$+15 \mathrm{~dB}$ & -108 & 0.303 & 2.2 & 45 & 0 & 42 & 0 & 2020 & 3080 & $100 \%$ \\
\hline$+20 \mathrm{~dB}$ & -112 & 0.143 & 2.49 & 49 & 0 & 49 & 0 & 2525 & 3030 & $100 \%$ \\
\hline$+25 \mathrm{~dB}$ & -117 & 0.095 & 1.73 & 83 & 0 & 197 & 0 & 2525 & 3030 & $100 \%$ \\
\hline$+30 \mathrm{~dB}$ & -120 & 0.011 & 1.67 & 228 & 0 & Instable & $\begin{array}{c}\text { Insta } \\
\text { ble }\end{array}$ & 2525.5 & 3570 & $100 \%$ \\
\hline$+32 \mathrm{~dB}$ & -122 & 0.008 & 1.1 & 291 & 0 & Instable & $\begin{array}{l}\text { Insta } \\
\text { ble }\end{array}$ & 2559 & 3030 & $100 \%$ \\
\hline$+34 \mathrm{~dB}$ & -124 & 0.005 & 0.463 & 594 & $6 \%$ & Instable & $\begin{array}{c}\text { Insta } \\
\text { ble }\end{array}$ & 2525 & 3540 & $100 \%$ \\
\hline$+36 \mathrm{~dB}$ & -126 & Instable & Instable & 2079 & 83 & Instable & $\begin{array}{l}\text { Insta } \\
\text { ble }\end{array}$ & 2020 & 2530 & $100 \%$ \\
\hline
\end{tabular}

Table 5. The measurement of TD-LTE 230MHz network for CPE

\begin{tabular}{|c|c|c|c|c|c|c|c|c|c|c|c|}
\hline \multirow{10}{*}{$\begin{array}{l}\text { CPE } \\
\text { (Multi- } \\
\text { frequenc } \\
\text { y) }\end{array}$} & Rsrp & $\begin{array}{c}\text { Downlink } \\
\text { snr }\end{array}$ & $\begin{array}{c}\text { Uplinks } \\
\mathrm{nr}\end{array}$ & $\begin{array}{c}\text { Uplink } \\
\text { speed } \\
(\mathrm{Mbps})\end{array}$ & $\begin{array}{c}\text { Downli } \\
\text { nk } \\
(\mathrm{kbps})\end{array}$ & $\begin{array}{c}\text { Packet } \\
\text { Delay } \\
(\mathrm{ms})\end{array}$ & $\begin{array}{c}\text { Packet } \\
\text { Loss } \\
(\%)\end{array}$ & $\begin{array}{c}\text { Packet } \\
\text { Delay with } \\
\text { 1k uplink }\end{array}$ & $\begin{array}{l}\text { Packe } \\
\text { t Loss } \\
(\%)\end{array}$ & $\begin{array}{l}\text { Switc } \\
\text { h-off } \\
\text { (ms) }\end{array}$ & $\begin{array}{c}\text { Switc } \\
\text { h- } \\
\text { on(ms }\end{array}$ \\
\hline & -80 & 28 & 24.6 & 1.51 & 289.5 & 147 & 0 & 130 & 0 & 2631 & 2020 \\
\hline & -90 & 28 & 24.6 & 1.51 & 290.6 & 145 & 0 & 131 & 0 & 2525 & 2525 \\
\hline & -100 & 27 & 18.4 & 1.14 & 290.2 & 143 & 0 & 146 & 0 & 2525 & 5555 \\
\hline & -105 & 26 & 13.6 & 0.714 & 290.2 & 148 & 0 & 143 & 0 & 2610 & 2640 \\
\hline & -110 & 25 & 10.6 & 0.6796 & 288.8 & 141 & 0 & 139 & 0 & 3030 & 2518 \\
\hline & -115 & 21 & 4.2 & 0.2837 & 208.3 & 157 & 0 & 142 & 0 & 5050 & 4033 \\
\hline & -120 & 18 & 2.2 & 0.1098 & 128.4 & 178 & $3 \%$ & 162 & 0 & 2525 & 3030 \\
\hline & -121 & 15 & -1 & 0.0545 & 127.6 & 178 & $2 \%$ & 167 & $3 \%$ & 3030 & 3030 \\
\hline & -122 & 14 & -2.2 & 0 & 126.7 & 287 & $8 \%$ & 268 & $10 \%$ & 2525 & 2065 \\
\hline
\end{tabular}

Table 6. The measurement of TD-LTE $230 \mathrm{MHz}$ network for LCM

\begin{tabular}{|c|c|c|c|c|c|c|c|c|c|c|c|}
\hline \multirow{10}{*}{$\begin{array}{c}\text { LCM } \\
\text { (Single } \\
\text { frequency) }\end{array}$} & Rsrp & $\begin{array}{c}\text { Downlink } \\
\text { snr }\end{array}$ & $\begin{array}{c}\text { Uplinks } \\
\mathrm{nr}\end{array}$ & $\begin{array}{l}\text { Uplink } \\
\text { speed( } \\
\text { Mbps) }\end{array}$ & $\begin{array}{c}\text { Downli } \\
\text { nk } \\
\text { (kbps) }\end{array}$ & $\begin{array}{l}\text { Packet } \\
\text { Delay } \\
(\mathrm{ms})\end{array}$ & $\begin{array}{l}\text { Packet } \\
\text { Loss } \\
(\%)\end{array}$ & $\begin{array}{c}\text { Packet } \\
\text { Delay } \\
\text { with 1k } \\
\text { uplink } \\
\end{array}$ & $\begin{array}{l}\text { Packe } \\
\text { t Loss } \\
(\%)\end{array}$ & $\begin{array}{c}\text { Switc } \\
\text { h-off } \\
(\mathrm{ms})\end{array}$ & $\begin{array}{c}\text { Switch } \\
- \\
\text { on(ms) }\end{array}$ \\
\hline & -80 & 25 & 21.6 & 45.6 & 15.5 & 187 & 0 & 154 & 0 & 3032 & 3030 \\
\hline & -90 & 25 & 21.2 & 45.5 & 15.4 & 181 & 0 & 162 & 0 & 2519 & 2525 \\
\hline & -100 & 24 & 20.6 & 45.2 & 15.1 & 193 & 0 & 164 & 0 & 3030 & 3030 \\
\hline & -105 & 23 & 20.4 & 45.2 & 14.3 & 185 & 0 & 181 & 0 & 2560 & 2670 \\
\hline & -110 & 20 & 19.4 & 44 & 10.8 & 227 & 0 & 253 & 0 & 3535 & 3030 \\
\hline & -115 & 18 & 16.2 & 33.04 & 6.7 & 239 & 0 & 316 & 0 & 2525 & 2525 \\
\hline & -120 & 13 & 12.2 & 18 & 3.3 & 403 & 0 & 410 & 0 & 3029 & 3030 \\
\hline & -123 & 10 & 10.2 & 16.6 & 2.1 & 462 & 0 & 431 & 0 & 2020 & 2525 \\
\hline & -127 & 9 & 9.2 & 16.6 & 2 & 517 & 0 & 501 & 0 & 3030 & 3032 \\
\hline
\end{tabular}




\section{The Security of Network}

The GPRS was originally designed to offer circuitswitched service (voice and circuit-switched data) primarily, with limited capability to offer low-bit-rate packet data service. When the amount of data is very large, there is no guarantee for the priority of key customers. Besides, the GPRS public network cannot support massive real-time online terminal, so most of the users in the standby state. The TD-LTE solution uses an array of end-to-end data protection methods, including 128-bit Advanced Encryption Standard (AES) and authentication encryption, to ensure high data security and reliability.

\section{References}

1. TSGR1\#17(00)1395, Adaptive Modulation and Coding (AMC), Adhoc\#24, HSDPA, 20th-24th Oct 2000

2. ZHONG Yu-Qing, WANG Hao, CHEN Bao-ren. Research on Application Principles of Communication Technologies in Smart Distribution Network, Electric Power Information Technology. 2013, 11(5):43-47. 